http://doi.org/10.48195/sepe2021-031

\title{
O PAPEL DA FISIOTERAPIA NA DIMINUIÇÃO DE PROBLEMAS ERGONÔMICOS: UMA REVISÃO INTEGRATIVA
}

Cecília Lorenzen; Gabriela Von Mühllen; Lara Boemo; Lucas Machado; Victória Ramos; Alecsandra Pinheiro Vendrusculo 


\section{RESUMO:}

A ergonomia é a ciência responsável pelo estudo da interação do ambiente de trabalho às características fisiológicas do trabalhador, sendo assim, os locais de trabalho incorporam a fisioterapia na busca da facilitação desta interação. O objetivo deste trabalho foi realizar uma revisão integrativa sobre a importância da fisioterapia para a diminuição de problemas ergonômicos. Para a realização deste artigo, utilizouse como metodologia a revisão integrativa, buscando dados de literaturas indexadas on-line e publicadas nos últimos 10 anos, sendo selecionados 3 artigos para a revisão. Com este estudo comprovou-se que, de maneira significativa, a fisioterapia atua no ambiente de trabalho com a prevenção, tratamento e reabilitação de problemas ergonômicos, sejam eles Lesões por Esforço Repetitivo ou Distúrbios Osteomusculares Relacionados ao Trabalho.

Palavras-chave: Fisioterapia; Ergonomia, Distúrbios Osteomusculares Relacionados ao Trabalho.

Eixo Temático: Atenção Integral e Promoção à Saúde (AIPS): projetos que integram o desenvolvimento de novas práticas, serviços e tecnologias em saúde relacionadas à atenção integral, ações educativas de valorização da estratégia de saúde no apoio à promoção e à prevenção à saúde da comunidade, visando a uma melhor qualidade de vida, bem como a pesquisa translacional em saúde. 


\section{INTRODUÇÃO:}

Ergonomia é a ciência responsável por estudar a relação do indivíduo com o seu ambiente de trabalho, analisando se a atividade laboral não está prejudicando-o (SILVA, 2005). Segundo a ABERGO (Associação brasileira de ergonomia) a ergonomia é, a adaptação do trabalho às características fisiológicas e psicológicas do trabalhador, ou seja, ela é a adaptação e facilitação do trabalho para o homem, preservando assim a sua saúde e bem-estar.

A ergonomia está presente na nossa história há muito tempo. Desde a idade pré-histórica até os dias atuais o ser humano adotou métodos de trabalho para melhorar a eficiência e consequentemente proporcionar uma melhor qualidade de vida para si e seus familiares. Os conceitos ergonômicos foram se desenvolvendo no decorrer dos anos e se adaptando, buscando sempre o melhor para os indivíduos. (OLIVEIRA, 2017).

Partindo do pressuposto que as pessoas passam a maior parte do tempo em locais de trabalho, a ergonomia torna-se fundamental e precisa estar presente no diaa-dia das empresas por ser a ciência que adapta o ambiente de trabalho ao indivíduo. Mais que apenas visar o lucro, os empregadores devem se responsabilizar por manter um ambiente adequado para uma jornada de trabalho eficiente a seus funcionários. (Ribeiro e Santana, 2015)

Em vista desses fatores, foi criado o conceito de DORT (Distúrbios osteomusculares relacionados ao trabalho) que são empregados quando o funcionário está exposto a riscos de má organização (excesso de jornada sem pausas, pressão dos chefes, poucos funcionários funções repetitivas) e também há riscos relacionados

Cecilia da Silveira Lorenzen, UFN email: cecilialorenzen8@gmail.com;

Gabriela Von Muhlen, UFN email: gabrielamuhlenvon@gmail.com;

Lara Argenta Boemo, UFN email: boemolara@gmail.com;

Lucas Machado Araujo, UFN email: lucasmachadoa3@gmail.com;

Victória Griebeler Ramos, UFN email: victoriaramosg7@gmail.com; 
ao ambiente (falta de um mobiliário adequado e confortável, ruídos, má iluminação), esses riscos podem ser evitados se colocados em prática os conceitos da ergonomia.

Para proporcionar a ergonomia, há uma equipe multidisciplinar que trabalha visando a melhora da qualidade de vida do trabalhador. $O$ fisioterapeuta faz parte dessa equipe multidisciplinar, tem papel fundamental nessa área, por ser um membro com sólida formação científica (TALO et al., 2010).

Esse profissional trabalha com o desenvolvimento de técnicas de prevenção, avaliação, tratamento e reabilitação que, utilizando programas de orientações e promoção à saúde, atua nos três níveis de atenção. Tais intervenções melhoram o desempenho e produtividade no trabalho (BAÚ; KLEIN, 2010).

Portanto, o objetivo deste trabalho é realizar uma revisão integrativa sobre a importância da fisioterapia para a diminuição de problemas ergonômicos.

\section{METODOLOGIA:}

O método de estudo escolhido para a realização desse artigo foi o de uma revisão integrativa. Essa prática proporciona vastas informações sobre o tema e questões abordadas, o autor pode fazer essa pesquisa no intuito de revisar, analisar, estudar, solucionar e definir conceitos. Um ponto chave, é que o estudo é feito com base em experiências próprias, que se tornarão pontos de discussão teórica. (Mendes et. al, 2008)

Segundo Souza, Silva e Carvalho (2010, p.102-6) considerando a necessidade de garantir práticas de saúde baseadas em evidências científicas, a revisão integrativa é considerada uma ferramenta ímpar na área da saúde, pois combina as pesquisas disponíveis sobre temas específicos e orienta a prática com base no conhecimento científico.

O processo de elaboração desta revisão integrativa começou com a elaboração da pergunta norteadora, busca ou amostragem na literatura, coleta de 
dados, análise crítica dos estudos incluídos, discussão dos resultados e apresentação da revisão integrativa.

Para seleção de literaturas foram utilizadas as seguintes bases de dados: LILACS, SCIELO, PUBMED e MEDLINE, consideradas importantes bases científicas de abrangência internacional. Além disso, optou-se por incluir um limite de ano para a publicação dos estudos, incluindo, desssa forma, artigos publicados entre os anos de 2010 e 2020.

Dessa forma, os critérios de inclusão para a amostra foram: artigos que abordassem a temática do papel da fisioterapia na diminuição de problemas ergonômicos, publicados em ][português e inglês durante o período de 2010 a 2020 . Foram utilizados os seguintes descritores indexados no DeCS: Fisioterapia; Ergonomia; Physiotherapy; Phisical Therapy; Ergonomics; Problem reduction.

Por fim, para a realização da base de dados foram selecionados os operadores booleanos: Fisioterapia AND ergonomia OR Physioyherapy AND ergonomics para assim, poder auxiliar na consulta rápida e no armazenamento de arquivos. Dessa forma, procurou-se ampliar o âmbito da pesquisa, minimizando possíveis vieses nessa etapa do processo de elaboração da revisão integrativa.

\section{RESULTADOS:}

As buscas nas bases de dados resgataram um total de 197 artigos publicados entre os anos de 2010 e 2020, sendo selecionados para a amostra apenas três artigos provenientes das bases de dados. 


\section{Qual o papel do físioterapeuta na diminuição de problemas}

ergonômicos?

0

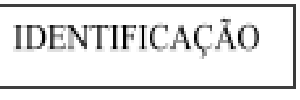

INCLUSÃO

\section{SELEÇÃO}

Artigos localizados por meio de pesquisa em base de dados: 197

\section{Artigos excluídos: 185}

Artigos selecionados após leitura

de título e resumo: 12

Artigos excluídos: 9

Artigos incluídos após leitura na

integra e aplicaçũo dos critérios de inclusăio e exclusão: 3

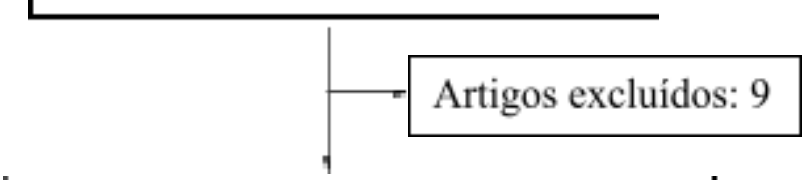

Scielo: 23

PubMed: 49

Lilacs: 29

MedLine: 96
Scielo: 2

PubMed: 1

Lilacs: 0

MedLine: 0 
Quadro 1. Características gerais dos artigos selecionados para a amostra $(n=3)$.

\begin{tabular}{|c|c|c|c|c|}
\hline Autor/Ano & Metodologia & Amostra & $\begin{array}{l}\text { Principais } \\
\text { Resultados }\end{array}$ & Objetivo \\
\hline $\begin{array}{l}\text { Moriguchi, } \\
\text { Cristiane; } \\
\text { Trevizani, } \\
\text { Taísa; } \\
\text { Oliveira, Ana; } \\
\text { Coury, } \\
\text { Helenice. } \\
2013\end{array}$ & $\begin{array}{l}\text { Estudo } \\
\text { Experimental }\end{array}$ & $\begin{array}{l}679 \\
\text { trabalhadores } \\
(192 \\
\text { trabalhadores } \\
\text { da indústria, } \\
128 \\
\text { profissionais de } \\
\text { enfermagem e } \\
359 \text { operadores } \\
\text { de } \\
\text { Teleatendimento } \\
\text { ) }\end{array}$ & $\begin{array}{l}\text { A distribuição } \\
\text { dos resultados } \\
\text { variou } \\
\text { consideravelme } \\
\text { nte entre os } \\
\text { grupos. Houve } \\
\text { valores } \\
\text { semelhantes a } \\
\text { alguns pontos } \\
\text { de corte e } \\
\text { outros } \\
\text { diferentes. Os } \\
\text { diferentes } \\
\text { pontos de corte } \\
\text { propostos pela } \\
\text { literatura não } \\
\text { identificaram } \\
\text { quantidades } \\
\text { similares de } \\
\text { trabalhadores } \\
\text { com altos } \\
\text { níveis de } \\
\text { necessidade de } \\
\text { descanso. }\end{array}$ & $\begin{array}{l}\text { Comparar a } \\
\text { utilização de } \\
\text { diferentes } \\
\text { parâmetros } \\
\text { matemáticos } \\
\text { para } \\
\text { interpretação } \\
\text { dos dados da } \\
\text { Enede, sendo } \\
\text { eles tercil, } \\
\text { quartil e } \\
\text { média, assim } \\
\text { como pontos } \\
\text { de corte já } \\
\text { sugeridos pela } \\
\text { literatura, no } \\
\text { sentido de } \\
\text { investigar o } \\
\text { comportament } \\
\text { o desses } \\
\text { parâmetros na } \\
\text { identificação } \\
\text { de altos níveis } \\
\text { de necessidade } \\
\text { de descanso }\end{array}$ \\
\hline
\end{tabular}




\begin{tabular}{|c|c|c|c|c|}
\hline $\begin{array}{l}\text { Rothstein, } \\
\text { Joice; } \\
\text { Berndt, } \\
\text { Angélia; } \\
\text { Moraes, } \\
\text { João; } \\
\text { Lanferdini, } \\
\text { Fábio. } 2013\end{array}$ & $\begin{array}{l}\text { Pesquisa } \\
\text { Pré-experimen } \\
\text { tal }\end{array}$ & \begin{tabular}{|l|}
328 \\
trabalhadores
\end{tabular} & $\begin{array}{l}\text { Predominância } \\
\text { de mulheres e } \\
\text { a idade dos } \\
\text { indivíduos } \\
\text { variou entre } 17 \\
\text { e 44 anos. Os } \\
\text { resultados } \\
\text { mostraram um } \\
\text { grande impacto } \\
\text { do estudo, } \\
\text { devido a a } \\
\text { questões do } \\
\text { questionário. } \\
\text { Nas quais, } \\
\text { mudaram com } \\
\text { a aplicação do } \\
\text { estudo, } \\
\text { obtendo } \\
\text { resultado } \\
\text { positivo }\end{array}$ & $\begin{array}{l}\text { Avaliar o } \\
\text { impacto de um } \\
\text { programa } \\
\text { interativo de } \\
\text { sensibilização } \\
\text { em Ergonomia } \\
\text { em relação ao } \\
\text { conhecimento } \\
\text { em segurança } \\
\text { e saúde de } \\
\text { trabalhadores } \\
\text { de uma } \\
\text { indústria têxtil. }\end{array}$ \\
\hline $\begin{array}{l}\text { Franchi, } \\
\text { Uerley; } \\
\text { Carregaro, } \\
\text { Rodrigo; } \\
\text { Souza, } \\
\text { Letícia; } \\
\text { Penha, } \\
\text { Arquimedes; } \\
\text { Padula, } \\
\text { Rosimeire. } \\
2019\end{array}$ & $\begin{array}{l}\text { Estudo } \\
\text { Transversal }\end{array}$ & $\begin{array}{|lr|}\text { Foi enviado } \\
\text { convite a todos } \\
\text { os participantes } \\
\text { legalmente } & \\
\text { registrados } & \text { no } \\
\text { Conselho } & \\
\text { Regional } & \text { de } \\
\text { Fisioterapia } & \text { e } \\
\text { Terapia } & \\
\text { Ocupacional } & \\
\text { (CREFITO) } & \text { do } \\
\text { Brasil } & \\
\end{array}$ & $\begin{array}{l}\text { Um total de } 153 \\
\text { PTs OHE } \\
\text { retornaram a a } \\
\text { pesquisa. A } \\
\text { média de idade } \\
\text { foi de } 35,6 \\
\text { anos, o tempo } \\
\text { na área de } \\
\text { OHE foi de } 8,5 \\
\text { anos, a maioria } \\
\text { foram } \\
\text { mulheres. Os } \\
\text { OHE PTs } \\
\text { relataram } \\
\text { satisfação com } \\
\text { seu } \\
\text { desempenho } \\
\text { profissional. }\end{array}$ & 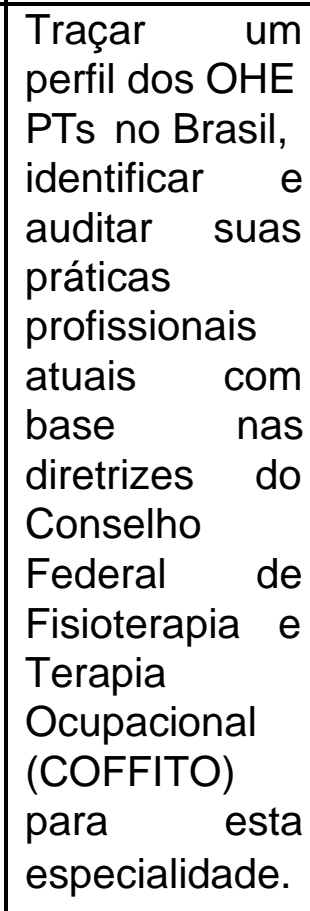 \\
\hline
\end{tabular}




\section{DISCUSSÃO:}

A análise dos resultados sobre a importância da fisioterapia para a redução de problemas ergonômicos mostra-se positiva, ou seja, quanto maior a intervenção fisioterapêutica no dia a dia dos trabalhadores, melhor a ergonomia e a produtividade dos mesmos. Sendo assim, os resultados dessa revisão corroboram com os achados na literatura, que mostra de forma explícita a necessidade da intervenção da fisioterapia no cotidiano de uma empresa.

"O Brasil possui a maior taxa de doenças ocupacionais e acidentes de trabalho da América Latina". Essa afirmação relata o quão precário são os cuidados com os trabalhadores nas empresas brasileiras e reafirma a importância da adoção de práticas ergonômicas no cotidiano dos trabalhadores, pois com elas irá ocorrer uma diminuição de acidentes e doenças entre os indivíduos, logo, melhorando a qualidade de vida do trabalhador, garantindo saúde e segurança. (ROTHSTEIN et al., 2013).

A ergonomia classifica os fatores de danos ao trabalhador em duas formas, sendo elas: Fatores de risco para lesões por esforço repetitivo (LER) e em Distúrbios osteomusculares relacionados ao trabalho (DORT). Ambas causadas por um ritmo de trabalho acelerado, esforços e movimentos repetitivos, número impróprio de funcionários, móveis inadequados, ausência de pausas para o descanso e longas jornadas de trabalho.

Para esses fatores serem corrigidos é necessária uma equipe de profissionais: psicólogos para auxiliar no estresse do cotidiano, arquitetos para ajustar a mobília de forma adequada, juntamente com engenheiros e por fim, fisioterapeutas que são essenciais para promover atividades de alongamentos durante as pausas do trabalho e orientar os indivíduos durante a realização das suas tarefas.

O fisioterapeuta possui um papel extremamente fundamental no campo da ergonomia, pois é ele que vai orientar os funcionários a adotar uma postura adequada no decorrer da jornada de trabalho, juntamente com adequações e 
orientações para os trabalhadores que precisam carregar e transportar pesos ou também que fazem atividades repetitivas diariamente.

Juntamente com o auxílio durante a prática do trabalho existe um método que as empresas e o fisioterapeuta podem adotar que são pausas na jornada de trabalho com a aplicação de exercícios de alongamento para os trabalhadores (MRIGUCHI et al., 2013). Isto, além de promover alívio da tensão muscular, também ajuda no preparo dos músculos para atividades, melhora a circulação sanguínea, previne lesões, melhora as habilidades execução dos movimentos, previne de tendinites e LER e por fim, ajuda a aliviar o estresse e as tensões.

É notável que a fisioterapia e a ergonomia estão interligadas, já que as duas possuem o objetivo final de ofertar qualidade de vida para os indivíduos. Além disso, embora a especialidade só tenha sido reconhecida há alguns anos, muitos profissionais trabalham no campo a mais de 20 anos (FRANCHI et al., 2019).

Somado a isso, as universidades que possuem o curso de fisioterapia tornam a disciplina de ergonomia obrigatória para os acadêmicos. Visto que a ergonomia é fundamental no cotidiano dos trabalhadores, juntamente com a fisioterapia. (Ribeiro, 2017)

"O fisioterapeuta do trabalho avalia os pacientes, estabelece o diagnóstico fisioterapêutico, planeja estratégias de intervenção, implementa ações de intervenção, educa em saúde, gerencia serviços de saúde, e além de executar atividades técnicocientíficas, trabalha promovendo segurança." (RIBEIRO, 2017). Isto reafirma que o profissional da fisioterapia promove o que é necessário para a implantação da ergonomia e para melhorar as condições dos indivíduos durante aatividade laboral, já que ele avalia, reeduca os funcionários e executa atividades para o bem-estar dos mesmos.

Em suma, torna-se perceptível a importância do fisioterapeuta na área da ergonomia, visando a qualidade de vida do trabalhador. Nesse sentido, o fisioterapeuta não atua apenas não atua somente na cínica de fisioterapia ou ambiente hospitalar, ele também estará inserido na origem dos problemas, tornando este um diferencial da Fisioterapia do Trabalho (Ruardo e Véras 2015 


\section{CONCLUSÃO:}

De acordo com estudo realizado neste artigo, conclui-se que a observação dos diversos fatores ergonômicos no ambiente de trabalho é imprescindível, pois influenciam e interferem na saúde do trabalhador. A partir desta constatação, verificase a necessidade da adoção de novos métodos de gestão do ambiente laboral, que inclui a formação de uma equipe multiprofissional especializada, que atenda esta demanda, visando a qualidade de vida do trabalhador. Neste sentido, o fisioterapeuta, que faz parte dessa equipe, tem papel fundamental nesse cenário, pois a ergonomia e a fisioterapia estão diretamente associadas.

Adotando novas tecnologias para as empresas, a aplicação de métodos ergonômicos é fundamental, pois aumenta a produtividade, a qualidade do trabalho, a motivação e a qualidade de vida no ambiente laboral, prevenindo doenças ocupacionais e eventuais lesões osteomusculares decorrentes do esforço repetitivo no ambiente de trabalho. Por esse motivo, a intervenção do fisioterapeuta é indispensável, pois este profissional tem sólida formação científica para auxiliar as pessoas a encarar o dia a dia de forma mais dinâmica e saudável. 


\section{REFERÊNCIAS:}

BAÚ, L.M; KLEIN A.A. O reconhecimento da especialidade em fisioterapia do trabalho pelo COFFITO e Ministério do Trabalho/CBO: uma conquista para a fisioterapia e a saúde do trabalhador. Rev. Brasil. Fisiot. Ano 2010, v. 13, n. 2, p. 5 - 6.

FRANCHI, M, et al. Fisioterapeutas em saúde ocupacional e ergonomia no Brasil: investigação do perfil sociodemográfico e práticas profissionais. Fisioterapia: teoria e prática. 2019. Acessado em 05 de Dez de 20

MORIGUCHI, C, et al. Avaliação de diferentes parâmetros para interpretar

a necessidade de descanso em ergonomia. Fisioter Mov. 2013 set/dez; 26: página 823-33. Acessado em 05 de Dez de 2020.

OLIVEIRA, Ana Flavia. Conheça um pouco da história da ergonomia. Blog da Beercorp, 13 de Nov. de 2017.

RIBEIRO, Doriléia Cristina do Amaral. A importância da fisioterapia juntamente com a ergonomia no ambiente de trabalho: revisão bibliográfica. Portal bio cursos, p. 10, Manaus, 2017.

ROTHSTEIN, J, et al, Impacto de uma metodologia interativa de ergonomia de conscientização. Fisioter Pesq. 2013; 20: 11-16. Acessado em 05 de Dez de 2020.

SANTTOS, Jaddy. 10 benefícios para o alongamento muscular. Hammer fitness club, 22 de FEV. de 2018.

SOUZA, Marcela Tavares de; SILVA, Michelly Dias da; CARVALHO, Rachel de. Revisão integrativa: o que é e como fazer. Journal Einstein, São Paulo, v. 8, n. 1, p. 102-6, mar. 2010.

TALO, S, et al. Uma investigação empírica do modelo conseqüência da doença biopsicossocial : psicológica deficiência, incapacidade e handcap em pacientes com dor crônica. Deficiência e Reabilitação. v. 17, n. 6, p. 28-92, 2010. Acessado em 20 de Nov de 2020. 
